\title{
A Rare Case of Chylothorax in a Patient with Schimmelpenning Syndrome
}

\author{
Bettina Schlolaut ${ }^{1}$ Hans Heinz Schild ${ }^{2}$ Joachim Pfannschmidt ${ }^{1}$ Dirk Kaiser ${ }^{1}$ \\ ${ }^{1}$ Department of Thoracic Surgery, Lung Clinic Heckeshorn at HELIOS \\ Hospital Emil von Behring, Berlin, Germany \\ 2 Department of Radiology, University of Bonn, Bonn, Germany \\ Address for correspondence Joachim Pfannschmidt, MD, Department \\ of Thoracic Surgery, Lung Clinic Heckeshorn at HELIOS Hospital Emil \\ von Behring, Walterhöferstr 11, Berlin 14165, Germany \\ (e-mail: Joachim.Pfannschmidt@helios-kliniken.de).
}

Thorac Cardiovasc Surg Rep 2014;3:64-66.

\begin{abstract}
Chylothorax originating in a patient with Schimmelpenning syndrome is rare and poses a problem in diagnosis and treatment. A 22-year-old male was admitted with dyspnea indicative of a large pleural chylous effusion. Besides conservative dietary treatment measures, the chylous effusion was drained $(2,000 \mathrm{~mL} /$ day). Computed tomography-

Keywords

- lung

- rare disorders

- pleural disease

- thoracic duct lymphography after ligation of the thoracic duct and pleurectomy revealed a small collateral flow of chylous fluid toward the chest wall and entering the thorax. Eventually, local radiation therapy with 36 Gy effectively treated the chylothorax. Five months later, an epitheloid angiosarcoma developing from a preexisting cutaneous lesion was detected and treated by surgical resection.
\end{abstract}

\section{Introduction}

Chylous leaks, such as chylothorax, are uncommon effusions in nontraumatic patients, resulting from leakage of the thoracic duct and its tributaries. Schimmelpenning syndrome is a rare neurocutaneous disorder characterized by one or more sebaceous nevi of the face or scalp, in association with anomalies of the central nervous system, ocular or skeletal pathology. ${ }^{1}$ This article describes vascular malformations of Schimmelpenning syndrome and also lymphatic anomalies in very rare cases. ${ }^{2}$

\section{Case Report}

A 22-year-old male student, who was formerly diagnosed with Schimmelpenning syndrome, presented to the emergency room with shortness of breath and a feeling of pressure in the chest. Symptoms were aggravated 1 week prior to his admission. He had a 10-year history of right-sided leg lymphedema (-Fig. 1) and his right eye had been enucleated because of a teratoma at the age of 1 . The patient's skin showed multiple efflorescences suggestive of sebaceous nevi. Chest X-ray showed a right-sided pleural effusion (-Fig. 2). The patient was initially treated with a chest tube, which drained 2,000 $\mathrm{mL}$ chylous effusion and persisted despite parenteral nutrition. Computed tomography (CT)-lymphography revealed a leakage of the thoracic duct at the midthoracic level. The patient underwent thoracotomy with ligature of the thoracic duct, and radical pleurectomy of the right thorax. Because of severe postoperative nausea and vomiting, a brain scan was done which showed hypotrophy of the left hemisphere with enlarged subarachnoid spaces but no signs of increased intracranial pressure.

Despite additional treatment with the long-acting somatostatin analogue octreotide, chylous effusion continued at 2,000 $\mathrm{mL}$ /day. A repeated CT-lymphography showed the thoracic duct ligated and a small collateral flow of chylous fluid toward the chest wall and entering the thorax ( - Fig. 3). Interventional treatment by lymphatic embolization was impossible due to the dysplastic and ectatic lymphatic vascular system. Eventually, radiation therapy was administered at segment T9 to T12 with 36 Gy and subsequently the chest tube could be removed.

Five months later, the patient was readmitted in the hospital with a bleeding skin lesion located at the right calf. Histology of the resected specimen confirmed an epitheloid angiosarcoma of the skin (-Fig. 4).

During the course, the patient did well for 4 months but was then admitted to the intensive care department with severe exsiccosis, and dyspnea from chylous thoracic effusion and received

July 14,2014 accepted after revision

August 11, 2014

published online

October 19, 2014
DOI http://dx.doi.org/ $10.1055 / \mathrm{s}-0034-1394162$. ISSN 2194-7635. (c) 2014 Georg Thieme Verlag KG
Stuttgart · New York

License terms

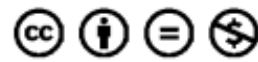




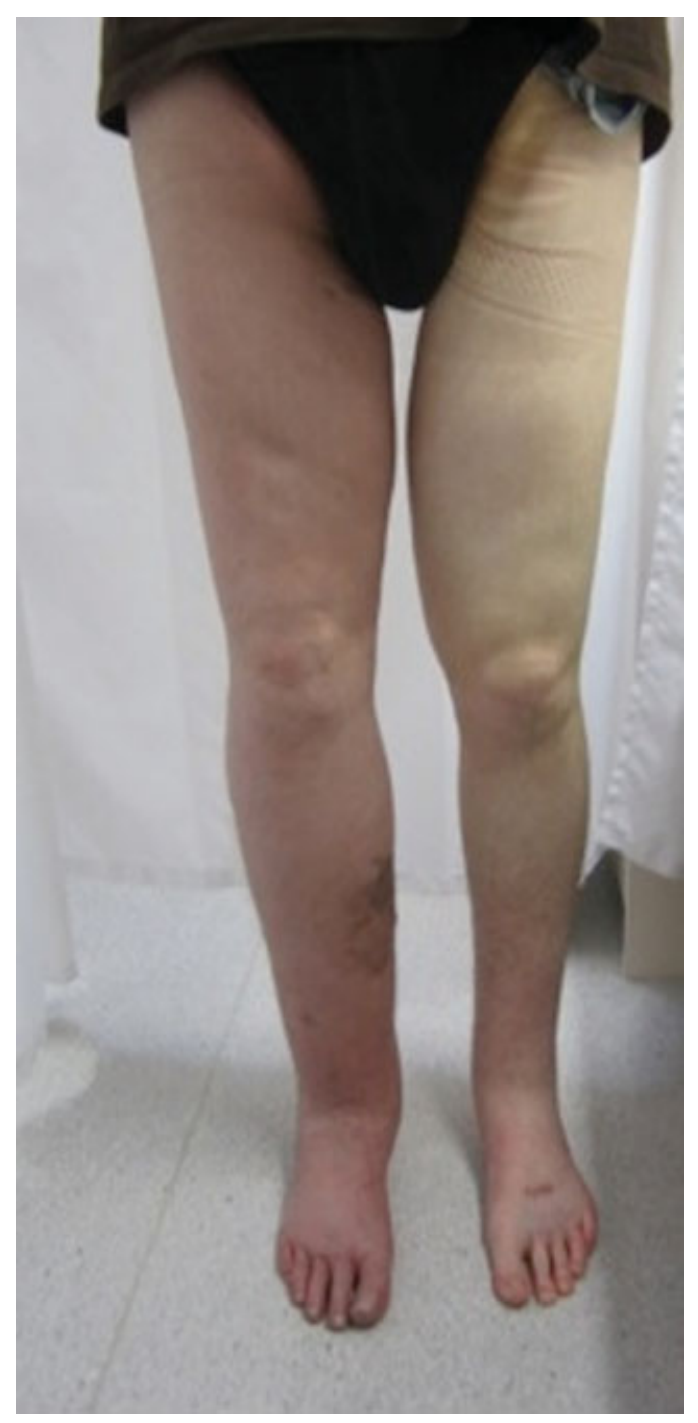

Fig. 1 Right-sided leg lymphedema with marked distension and local swelling (stasis edema). chylous ascites, and cachexia. Despite all supportive efforts, the patient succumbed due to renal insufficiency and septicemia.

\section{Comment}

Schimmelpenning syndrome is considered a rare disease, and is listed in the US-registry of the National Organization for Rare Disorders. It has been proposed that Schimmelpenning syndrome results from genetic mosaicism, with underlying genetic mutations of the HRAS gene and KRAS gene. ${ }^{3}$

The term Schimmelpenning syndrome has been widely used since 1962 and describes the classic triad of sebaceous nevi, seizures, and mental retardation. ${ }^{4,5}$ However, further studies revealed additional anomalies in the affected patients, and thus the diagnostic definition by the three symptoms was relativized. ${ }^{6}$

Also, vascular anomalies, such as hemangiomas or nevus flammeus, have been described, with the term Schimmelpenning syndrome being used nosologically imprecise. ${ }^{7}$

Lymphatic malformations are equally rarely seen and documented within a review of the literature in 3 of 119 patients. To our knowledge, only Greene et $\mathrm{al}^{2}$ reported two patients with chylothorax in a series of nine patients with Schimmelpenning syndrome.

The basic principles of chylothorax treatment include efficient drainage, complete lung expansion by chest tube drainage, and reduction of the chylous flow by dietary and medical treatment. Surgical options by video-assisted thoracic surgery or thoracotomy include ligature of the thoracic duct and pleurodesis by intrapleural irritants. However, in postoperative chylothorax up to $11 \%$ of the patients underwent repeat surgical procedures due to complications, and 9 to $15 \%$ experienced recurrences. . $^{8,9}$

In recent years, percutaneous embolization ${ }^{10}$ and radiotherapy ${ }^{11}$ have been suggested as further treatment options to avoid invasive procedures and as an alternative in recurrent chylothoraxes to obliterate the thoracic duct and adjacent lymphatic vessels.


Fig. 2 Posteroanterior and lateral chest roentgenogram demonstrating pleural effusion. 



Fig. 3 Computed tomography-lymphography showing the thoracic duct ligated and a leakage at the midthoracic level.

In previous years, surgical excision of the sebaceous nevus was considered the treatment of choice to prevent malignant degeneration; at present, such prophylactic measures are not considered necessary, as the estimated rate of malignant transformation seems to be low. ${ }^{12}$ In our case, an angiosarcoma developed out of a preexisting cutaneous lesion. This underlines the importance of close clinical observation of the cutaneous lesions in Schimmelpenning syndrome.

In conclusion, ectatic dysplastic lymphovenous malformations with lymphatic collateral flow in Schimmelpenning syndrome made ligation of the thoracic duct for chylothorax difficult. Alternative measures for lymphatic obliteration,

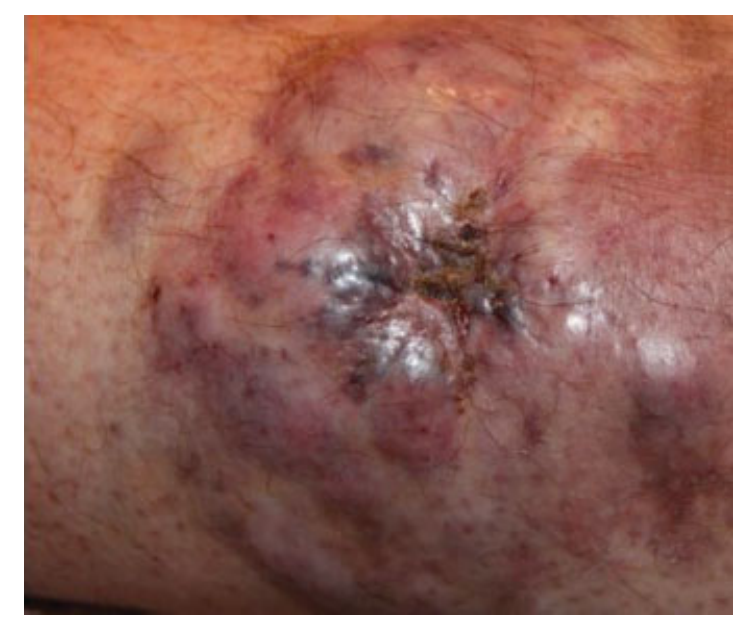

Fig. 4 Angiosarcoma developed at the lower right leg. such as local radiation therapy, are feasible. Close observation of concomitant symptoms is warranted.

\section{References}

1 Menascu S, Donner EJ. Linear nevus sebaceous syndrome: case reports and review of the literature. Pediatr Neurol 2008;38(3): 207-210

2 Greene AK, Rogers GF, Mulliken JB. Schimmelpenning syndrome: an association with vascular anomalies. Cleft Palate Craniofac J 2007;44(2):208-215

3 Groesser L, Herschberger E, Ruetten A, et al. Postzygotic HRAS and KRAS mutations cause nevus sebaceous and Schimmelpenning syndrome. Nat Genet 2012;44(7):783-787

4 SCHIMMELPENNING GW. Clinical contribution to symptomatology of phacomatosis. Fortschr Geb Rontgenstr Nuklearmed 1957; 87(6):716-720

5 Feuerstein RC, Mims LC. Linear nevus sebaceus with convulsions and mental retardation. Am J Dis Child 1962;104:675-679

6 Happle R. Epidermal nevus syndromes. Semin Dermatol 1995; 14(2):111-121

7 Solomon LM, Esterly NB. Epidermal and other congenital organoid nevi. Curr Probl Pediatr 1975;6(1):1-56

8 Zabeck H, Muley T, Dienemann H, Hoffmann H. Management of chylothorax in adults: when is surgery indicated? Thorac Cardiovasc Surg 2011;59(4):243-246

9 Shimizu K, Yoshida J, Nishimura M, Takamochi K, Nakahara R, Nagai K. Treatment strategy for chylothorax after pulmonary resection and lymph node dissection for lung cancer. J Thorac Cardiovasc Surg 2002;124(3):499-502

10 Cope C. Management of chylothorax via percutaneous embolization. Curr Opin Pulm Med 2004;10(4):311-314

11 Sziklavari Z, Allgäuer M, Hübner G, et al. Radiotherapy in the treatment of postoperative chylothorax. J Cardiothorac Surg 2013;8:72

12 Chou C-Y, Chen W-Y, Wang K-H, Chen T-J. Carcinosarcoma derived from nevus sebaceus. J Clin Oncol 2011;29(25):e719-e721 